\title{
COMO ABRIR A CAIXA DE PANDORA?: estratégias metodológicas para o estudo da polícia que mata
}

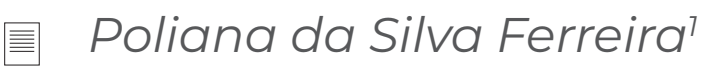

\section{Palavras-Chave}

metodologia/ polícia que mata/ auto de resistência/ pesquisa qualitativa/ pesquisa quantitativa

\section{SUMÁRIO}

\section{Introdução}

2. A caixa é fechada: os desafios no estudo da polícia que mata

3. A chave não é única: as estratégias metodológicas utilizadas pelos pesquisadores

3.1 Abordagens qualitativas

3.2 Abordagens quantitativas

\section{Considerações finais}

5. Referências

\section{Resumo}

Este texto tem por objetivo apresentar as estratégias metodológicas utilizadas por diferentes pesquisadores para estudar a polícia que mata em serviço. Assim, a partir de uma revisão de literatura sobre o tema, buscamos observar os mecanismos, percursos e desafios enfrentados por aqueles que se dedicam a estudar um campo que, no Brasil, ainda se mostra como uma caixa fechada, repleta de enigmas. A pesquisa busca contribuir para uma reflexão aprofundada em duas frentes. Por um lado, observar os desafios comuns às pesquisadoras e pesquisadores que atuam na área de segurança pública, e, por outro, os caminhos construídos por estes para produzir conhecimento neste campo. 


\section{HOW TO OPEN THE PANDORA'S BOX?: methodological strategies for the study of the police that kills}

害 Poliana da Silva Ferreira

\section{Keywords}

methodology/ police killings/

police report/ qualitative research/

quantitative research
This text aims to present the methodological strategies used by different researchers to study the police that kill in service. Thus, based on a review of the literature on the subject, we seek to observe the mechanisms, paths and challenges faced by those who study a field that, in Brazil, still appears as a closed box, full of enigmas. The research seeks to contribute to an in-depth reflection on two fronts. On the one hand, to observe the challenges common to researchers and researchers working in public security, and, on the other hand, the paths built by them to produce knowledge in this field. 


\section{Introdução}

Este texto' tem por objetivo observar como pesquisadoras e pesquisadores têm estudado a polícia que mata em serviço, no Brasil. Sabe-se que as polícias brasileiras estão entre as que mais matam em serviço no mundo. Segundo o Anuário do Fórum Brasileiro de Segurança Pública (2016), o país tem se destacado "em pesquisas internacionais por ser a nação que concentra o maior número de homicídios do planeta, coloca-se à frente do ranking da barbárie como o país cuja polícia mais mata e mais morre em seu cotidiano de trabalho" (p. 29).

O panorama numérico dessas mortes, apesar de nos dar apenas uma das dimensões do problema, nos permite observar um quadro nacional de distribuição dessas mortes. Assim, segundo o Anuário do Fórum Brasileiro de Segurança Pública (2016), apenas no ano de 2015, 3.320 pessoas foram vítimas de mortes decorrentes de intervenções policiais. Entre 2009 e 2015, o acúmulo foi de 17.688 mortos pela mesma causa.

O enfrentamento desse quadro, por meio de políticas públicas que visem à redução de tais índices, passa, necessariamente, pela construção de diagnósticos precisos a respeito da letalidade das ações policiais. Um trabalho que os pesquisadores têm encontrado inúmeras dificuldades para realizar.

Apesar de estarmos num Estado Democrático de Direito, aqui entendido como o Estado "que não tem apenas a obrigação de tratar os cidadãos de maneira igual perante a lei, mas também o dever de assegurar a justiça substantiva", devendo ser visto como "uma ferramenta indispensável para evitar a discriminação e o uso arbitrário da força"

\footnotetext{
Agradeço imensamente a leitura, os comentários e as críticas que este texto recebeu de Dan Kaminski, Felipe Freitas, Maira Machado e Riccardo Cappi.
}

(Vieira, 2007, p. 30-31), as pesquisadoras e os pesquisadores que se debruçam sobre o tema ${ }^{2}$ encontram uma verdadeira Caixa de Pandora: ${ }^{3}$ fechada, repleta de segredos e de contradições com o que se tem definido constitucionalmente como Estado Democrático de Direito.

Diante desse cenário, onde há uma polícia que mata excessiva e ilegalmente e que, na maioria das vezes, não é responsabilizada, como os pesquisadores podem contribuir para o fortalecimento do Estado Democrático de Direito e para a garantia de direitos humanos? Nesse contexto, interessa-nos saber de que forma os pesquisadores têm desvendado essa Caixa de Pandora. Com que métodos e técnicas eles têm enfrentado os desafios de estudar a polícia que mata em serviço?

Metodologicamente, buscamos responder essa pergunta fazendo um levantamento bibliográfico do que a academia tem produzido a respeito do tema desde a promulgação da Constituição Federal de 1988. Esse marco temporal foi escolhido em função do fato que a nova ordem constitucional inaugurou uma série de mecanismos que permitem à sociedade civil, pelo menos em tese, uma "vigilância crítica" (Abdo, 2011) sobre as instituições públicas.

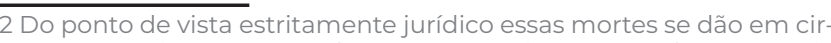
cunstâncias de suposto confronto com a polícia, que ao fazer o uso da força letal, encontra amparo legal nos processos de responsabilização em função da combinação dos artigos 23 do Código Penal: "Art. 23 Não há crime quando o agente pratica o fato: I - em estado de necessidade; II - em legítima defesa; III - em estrito cumprimento de dever legal ou no exercício regular de direito", com o artigo 292, do Código de Processo Penal: "Se houver, ainda que por parte de terceiros, resistência à prisão em flagrante ou à determinada por autoridade competente, o executor e as pessoas que o auxiliarem poderão usar dos meios necessários para defender-se ou para vencer a resistência, do que tudo se lavrará auto subscrito também por duas testemunhas" e com o 284, do mesmo diploma legal: "Art. 284. Não será permitido o emprego de força, salvo a indispensável no caso de resistência ou de tentativa de fuga do preso".
}

3 A Caixa de Pandora é um produto da mitologia grega, que designa um artefato entregue à primeira mulher criada por Zeus. Nela, estão presos todos os males do mundo. Aqui, a caixa com "todos os males do mundo" é representada pelos nós que têm inviabilizado a implementação do Estado Democrático de Direito no âmbito da Segurança Pública, mais especificamente, em torno da polícia que mata em serviço. Para saber mais sobre o mito de Pandora: https://www.significados.com.br/caixa-de-pandora/ 
Entre as mais de quarenta pesquisas encontradas na plataforma digital do Google Acadêmico ${ }^{4}$ filtramos aquelas que buscavam estudar o tema a partir de um viés empírico, independentemente da área em que os pesquisadores estivessem inscritos. $\mathrm{Na}$ etapa seguinte, categorizamos as pesquisas encontradas em função da abordagem adotada pelos pesquisadores - qualitativa ou quantitativa. Destas, selecionamos apenas nove ${ }^{5}$ que se encaixaram nos critérios: pesquisa empírica, coleta de dados realizada explicitamente pelo próprio pesquisador ou equipe, e variabilidade dos métodos. O resultado dessa revisão de literatura está organizado ao longo do texto.

O presente texto está dividido em duas partes principais. Na primeira, apresentaremos como a caixa está fechada, isto é, quais são as principais dificuldades relatadas pelas pesquisadoras e pesquisadores que estudaram a polícia que mata em serviço? Nesse sentido, buscamos na observação direta do campo e nas pesquisas empíricas, realizadas em diferentes áreas do conhecimento, os entraves, desafios e as barreiras encontradas frente às instituições e atores nesse âmbito.

Na segunda parte, nossa preocupação volta-se às estratégias e mecanismos utiliza-

\footnotetext{
4 Entramos com os termos: "homicídio decorrente de intervenção policial"; "auto de resistência"; "resistência seguida de morte"; "polícia que mata"; "homicídio praticado por policial", "homicídio por auto de resistência", além destes mesmos termos no plural.

5 São elas: (i) Atucaiados pelo Estado: as políticas de segurança pública implementadas nos bairros populares de Salvador e suas re presentações (1997-2007), de Vilma Reis (2005); (ii) "Autos de resistência": uma análise dos homicídios cometidos por policiais na cidade do Rio de Janeiro(2007-2017), coordenada por Michel Misse (2011); (iii) Indignos de Vida: a forma jurídica da política de extermínio de inimigos na cidade do Rio de Janeiro, Orlando Zaccone D'elia Filho (2013) (iv) Boletim de criminalidade: abril de 2013 (2013) e (v) Viés racial no uso da força letal pela polícia no Brasil(2014) produzidas por Jose Ignacio Cano Gestoso (vi) Desigualdade racial e segurança pública em São Paulo: letalidade policial e prisões em flagrante, coordenada por Jacqueline Sinhoretto (2014); (vii) "Confrontos" de ROTA: a intervenção policial com "resultado morte" no estado de São Paulo, de autoria de Henrique de Linica Macedo (2015); (viii) Carandiru não coisa do passado: um balanço sobre os processos, as instituições e as narrativas 23 anos após o massacre, sob coordenação de Maíra Rocha Machado e Marta Rodriguez Machado (2015); (ix) A resposta judicial para os homicidios envolvendo policiais no Brasil: uma análise quantitativa, publicada por Ludmila Mendonça Ribeiro e Igor Suzano Machado (2016)
}

dos por aqueles pesquisadores para traçar diagnósticos sobre problemas específicos, seja em relação às abordagens policiais em si, seja em relação a seu tratamento pelo sistema de justiça. ${ }^{6}$ Nessa seção, observamos que a chave não é única e que, portanto, os métodos e técnicas adotados para enxergar e construir o problema de pesquisa são também diversos. Por fim, arrematamos a discussão nas considerações finais.

\section{A caixa é fechada: os desafios no estudo da polícia que mata}

A letalidade das ações policiais é uma realidade no Brasil. De norte a Sul, têm-se relatos da polícia que mata. Para além de serem vistos como "casos isolados", os homicídios praticados por policiais - estaduais, militares ou civis, e federais - é um problema grave e persistente, e seu estudo demanda o enfrentamento de desafios de várias ordens por parte dos pesquisadores.

A seguir, apresentamos o resultado da categorização criada ao longo da revisão de literatura realizada, que nos permitiu a observação de três grupos de desafios, nomeados por nós a partir de sua natureza.

O primeiro deles é de ordem epistemológica, isto é, está ligado à ausência de definição clara sobre a natureza, as formas e "lugares" de observação do fenômeno e de seus limites conceituais; o segundo é de ordem estrutural, isto é, são aquelas barreiras para quem pretende estudar temas ligados à segurança pública de forma geral, e por fim, o terceiro, de ordem meta-estrutural, são os entraves relacionados especificamente à

\footnotetext{
6 Algumas pesquisas têm apontado que a letalidade das ações policiais tem continuidade com a ação dos atores do sistema de justiça, seja arquivando inquéritos, seja deixando de responsabilizar os agentes envolvidos nas abordagens que resultaram morte (Zaccone, 2015; Gloeckner \& Gonçalves, 2017). Por isso, decidimos observar também como os pesquisadores e pesquisadoras têm enxergado a letalidade policial em função do sistema de justiça, e as estratégias utilizadas para acessar e compreender o campo.
} 
polícia como objeto de estudo. Nesta seção, observaremos cada um deles.

A clareza na definição e na natureza do objeto estudado é um desafio que precede a formulação do problema de pesquisa para quem pretende se dedicar à polícia que mata em serviço. As "mortes decorrentes de intervenção policial"7, como passaram a ser chamadas recentemente as mortes oriundas de "autos de resistência", é uma categoria criada para unificar termos que, anteriormente, apesar de se referirem às mesmas ações, possuíam atribuições diversas nos diferentes estados brasileiros.

O termo é recente, mas, o fenômeno e a produção de dados referentes a estes não o são. As mortes praticadas por policiais têm sido estudadas no Brasil por diferentes pesquisadores, mais intensamente, a partir da última década do século XX, muito em função da agenda de pesquisa que se constituiu com a redemocratização do país, em 1988.

Portanto, não obstante a polícia brasileira ser historicamente violenta e pratique ações letais desde os seus primórdios (Pinheiro, 1997, Reis, 2005; Costa, 2005; Flauzina, 2006, Souza, 2010), é inevitável afirmar que a nova constituição permitiu a configuração de um Estado Democrático de Direito que, pelo menos do ponto de vista formal, se mostrou, por um lado, contrário às práticas de torturas e execuções arbitrárias e ilegais praticadas pelas polícias, e por outro, favorável à criação de mecanismos de accountability sobre as próprias polícias.

Os estudos realizados a partir dos anos 1990

\footnotetext{
7 Nomenclatura atribuída pela Resolução Conjunta $n^{\circ} 2$, de 13 de ou tubro de 2015, do Ministério da Justiça, do Departamento de Polícia Federal e do Conselho Superior de Polícia, que dispõe sobre os procedimentos internos a serem adotados pelas polícias judiciárias em face de ocorrências em que haja resultado lesão corporal ou morte decorrentes de oposição à intervenção policial. A proposta de alteração da expressão já havia sido mencionada pela Resolução $n^{\circ} 8$, da Secretaria de Direitos Humanos (SDH), de 2012.
}

apresentam uma diversidade - por vezes uma imprecisão - no que diz respeito a pelo menos três elementos. O primeiro deles está ligado à natureza do "auto de resistência", isto é, trata-se do próprio procedimento administrativo, do documento que encerra o procedimento ou do ato de matar em si?

O segundo relaciona-se às formas e "lugares" de observação do fenômeno, ou seja, observa-se quando e como a morte ocorre, como a administração a trata, como o juízo a trata, como o Tribunal do Júri julga ou o que acontece quando alguns casos alcançam o Tribunal de Justiça?

E, por fim, o terceiro está ligado aos limites conceituais, isto é, a categoria "auto de resistência" é nativa ou criada pelo pesquisador? A nomenclatura atribuída pelas práticas jurídicas - será a mesma usada pelo pesquisador? O que se pretende sugerir aqui é se o pesquisador fará uso da definição (jurídica) adotada pelos agentes estatais ou seu estudo formula conceitos próprios, distintos das definições atribuídas pelo Direito.

Popularmente, as abordagens policiais que resultam morte ficaram conhecidas por autos de resistência, ${ }^{8}$ homicídio decorrente de auto de resistência, auto de resistência com resultado morte, e, mais recentemente, morte decorrente de intervenção policial, ou ainda, morte decorrente de oposição à intervenção policial. A variação da nomenclatura ocorre em função da diversidade de expressões que eram utilizadas pelas polícias civis dos estados para se referir às mortes de civis ocorridas durante as ações policiais, e ela não chegou ao fim com a unificação proposta pelas resoluções promul-

8 Especialmente no Rio de janeiro, o uso do termo "auto de resistência" para se referir a tais mortes derivaria da referência feita pelos art. 284 e art. 292 do CPP (já mencionados) à lavratura do auto circuns284 e art. 292 do CPP (já mencionados) à lavratura do auto circuns2010; Zaccone D'Élia Filho, 2013). 
gadas e outros instrumentos normativos, ${ }^{9}$ na medida em que os pesquisadores, atores do sistema de justiça, veículos de comunicação e organizações da sociedade civil não se apropriaram da expressão legal, o que cria dificuldades na utilização de aspectos comparativos por regiões e/ou estados do país (Bueno, Cerqueira, \& Lima, 2013).

Um segundo problema, também de cunho epistemológico, são os limites conceituais do objeto. A diversidade de nomenclaturas e seu uso corrente por diferentes atores permitiram uma imprecisão no uso de um conceito que pode se referir a questões juridicamente distintas. É o que chamaremos aqui de "substancialização de uma resposta jurídica", 10 isto é, ao fato de que o Estado nomeou a resposta às mortes decorrentes de abordagens policiais de uma forma (em âmbito administrativo e processual penal) como maneira de ver e tratar o fenômeno - e os demais atores sociais a adotam irrefletidamente para nomear fenômenos em si.

Aqui cabe frisar que o desafio ora identificado é também um reflexo do próprio campo empírico, que obriga os pesquisadores e pesquisadoras a recortarem com precisão o objeto a ser estudado, o que ocorre, inevitavelmente, segundo suas próprias representações, leituras e experiências pessoais que são ainda, interpretadas e apropriadas de distintas maneiras.

9 Além das Resolução $n^{\circ}$ 8, da Secretaria de Direitos Humanos (SDH) de 2012, que dispõe sobre a abolição de designações genéricas para se referir a tais ocorrências, e a Resolução Conjunta n 2 de 13 de ou tubro de 2015, do Ministério da Justiça, do Departamento de Polícia Federal e do Conselho Superior de Polícia, já mencionada, cabe destacar as recomendações do Programa Nacional de Direitos Humanos PNDH-3, através do Decreto da Presidência da República n 7.037, de 21 de dezembro de 2009, e de importantes documentos internacionais como o Relatório do Relator Especial, Philip Alston, sobre as execuções extrajudiciais, sumárias ou arbitrárias referente a sua missão ao Brasil (4 a 14 de novembro de 2007) e Relatório 141/11, da Comissão interamericana de Direitos Humanos/OEA para o Estado Brasileiro (de 31 de outubro de 2011), ambos recomendando a eliminação dos registros de mortes pela polícia por meio de autos de resistência, apesar do caráter recomendatório e da baixa capacidade normativa.

10 Agradeço ao professor Riccardo Cappi por sugerir este termo para sintetizar a ideia básica.
Além disto, as expressões "auto de resistência", "resistência seguida de morte", "mortes cometidas por policiais" referem-se às mortes de civis ocorridas durante as ações policiais, mas essas nomenclaturas escondem tipologias distintas, que envolvem problemas distintos e, portanto, resolução distinta. Trata-se de, ao menos, dois fenômenos.

Primeiro, os "autos de resistência", do ponto de vista jurídico-administrativo constituíram um procedimento que se encerrava com a lavratura de um documento. Em contexto de abordagem policial com resultado morte, o "auto de resistência" podia ser definido como:

\section{o termo lavrado pelo executor (ou execu- tores) de uma prisão, quando se depara com resistência e necessita empregar força física para vencê-la. Trata-se de um documento formal em que o executor narra, de forma minuciosa e clara, todas as circunstâncias do fato que o levou ao emprego de força que, inclusive, pode ter provocado lesões ou morte do agente da resistência ativa. Será assinado por duas testemunhas de preferência que tenham assistido ao desenrolar do fato, pelo me- nos parcialmente. Para melhor segurança dos policiais, as testemunhas devem ser insuspeitas e idôneas (Assis, 2002, p. 105).}

Esse documento comporia mais tarde um inquérito policial militar, que a pedido do Ministério Público seria, como ocorre por todo o Brasil, arquivado sob a justificativa de uma excludente de ilicitude (Misse et al. 2013; Zaccone, 2015; Gloeckner \& Gonçalves, 2017).

Segundo, as mortes de civis ocorridas durante as ações policiais podem resultar de homicídios dolosos - quando o policial age com animus necandir sob o argumento de uma excludente de ilicitude ou não - ou culposos, quando derivam de negligência, imperícia ou imprudência.

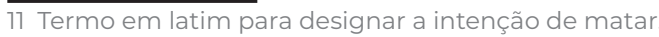


Ocorre que, inúmeras vezes, essa categorização só é feita com precisão, do ponto de vista jurídico, após o julgamento em plenário dos réus do Tribunal do Júri, ou seja, até que isso ocorra - fato que pode levar anos -, estaremos falando de fatos distintos, cujo enfrentamento, pode estar no plano da formação, do treinamento, da seleção dos policiais, na troca das empresas fornecedoras de armamento, na distribuição do efetivo, ou mesmo, com foco na mudança da chamada "cultura policial de extermínio" (Gloeckner \& Gonçalves, 2017, p. 198), só para citar alguns exemplos.

Essa indistinção traz a dificuldade de unirmos categorias jurídicas distintas, cujas consequências são também distintas. No plano da pesquisa, ela inviabiliza a consolidação de dados a respeito do acompanhamento desses casos ao longo do sistema de justiça, pois a alteração da categoria administrativa "morte decorrente de intervenção policial", por exemplo, para homicídio doloso ou culposo, não é divulgada de forma ampla e sistematizada pelos Tribunais de Justiça, ou pelos Ministérios Públicos dos Estados, o que dificulta a identificação dos casos na esfera judicial.

Misse (2013) pontua, em pesquisa realizada a respeito das abordagens policiais com resultado morte e de seu tratamento ao longo do sistema de justiça criminal, que:

É preciso esclarecer que a identificação sistemática dos inquéritos classificados como "Provenientes de Auto de Resistência" somente é possível na fase policial, através do banco de dados informatizado da Polícia Civil, mas nas fases posteriores do processamento tal identificação não pode ser feita. Isso porque, a partir da classificação jurídica do Ministério Público, desaparece a classificação administrativa da polícia, substituída pela classificação do Código Penal (Misse et al., 2013, p. 27).
Esse fato também foi identificado e relatado por outros pesquisadores no Rio de Janeiro e na Bahia (Miranda, Dirk, \& Pita, 2007; Zaccone, 2015; Ferreira, 2017), que também expuseram como um problema para a produção de pesquisas na área a ausência de uniformização do termo para nomear aquelas ocorrências.

Em função das dificuldades de acesso aos inquéritos relativos a abordagens policiais que resultaram morte, arquivados a pedido do Ministério Público, a entrada privilegiada de pesquisadores em determinado campo deve ser explicitada, sob pena de sua pesquisa não ter replicabilidade no campo acadêmico, elemento considerado uma característica fundamental na constituição de uma pesquisa acadêmica (Webley, 2010). Além disso, a explicitação do caminho triIhado pelos pesquisadores facilita a continuidade da produção de conhecimento, na medida em que permite que um outro pesquisador possa adotar estratégias que considerem as dificuldades apontadas pelo pesquisador anterior.

O segundo desafio, de ordem estrutural, refere-se às barreiras comuns àqueles e àquelas que pretendem estudar temas ligados à segurança pública de forma geral. Poderíamos citar três exemplos: a ausência de dados públicos, que permitam um diagnóstico acerca dos impactos da implementação de planos estaduais de segurança pública para além das estatísticas produzidas sobre crimes contra o patrimônio e contra a vida - nestes últimos, inclusive, em regra, são excluídos os homicídios praticados por policiais; os parâmetros utilizados pelas Secretarias de Segurança Pública dos estados para produzir políticas públicas para reduzir aqueles índices; e os critérios de distribuição orçamentária para enfrentar o problema. 
Esses exemplos são dificuldades comuns aos pesquisadores do âmbito da segurança pública e estão relacionadas às práticas autoritárias herdadas das ditaduras pelas quais passamos. Estas geram a precariedade, ou em alguns casos a inexistência, de dados públicos a respeito da segurança pública no país, e isto ainda é uma constante. Segundo afirmam Samira Bueno e Renato Sérgio de Lima,

Inexiste no Brasil uma tradição na sistematização de informações sobre violência policial. As instituições pioneiras neste tipo de mapeamento foram as organizações da sociedade civil em uma lógica "denuncista" das violações de direitos humanos. No âmbito federal, não existem ações periódicas que induzam a divulgação desses dados, tampouco pesquisas de vitimização que dimensionem o fenômeno. As corregedorias de polícia são responsáveis pelo registro e a apuração dos casos em que há violência ou abuso, mas não adotam uma sistemática de divulgação das informações, não existindo uma padronização quanto à forma de registro destes casos (2012, p. 104).

Ao lado disso, quando os dados existem, estes nem sempre são consistentes, e, consequentemente, confiáveis. Ao analisar a qualidade das informações produzidas sobre mortalidade violenta nas unidades da federação, Daniel Cerqueira (2013) observou sérios problemas em pelo menos três dimensões das informações produzidas pelo Sistema de Informações sobre Mortalidade:12 deficiência na abrangência e cobertura dos registros de óbitos, classificação inadequada de algumas causas do óbito e equívocos no preenchimento das informações relacionadas à vítima e ao incidente.

O terceiro desafio, de ordem metaestrutural, são os entraves relacionados especificamente à polícia como objeto de estudo. Esta categoria foi criada diretamente a partir dos relatos descritos nas pesquisas observadas. O nome "metaestrutural" refere-se às barreiras que estruturam a estrutura, isto é, que enrijecem o campo inviabilizando a realização de pesquisas, seja porque os procedimentos são sigilosos, seja por conta da autonomia funcional das polícias dos estados, seja em função das desconfianças institucionais.

A violência policial letal ainda não é tratada no Brasil como um problema de segurança pública, que possa nos remeter a indicadores de qualidade em nosso Estado Democrático de Direito. Ao revés, ela nos remete ao que Oscar Vieira (2007) e Guilhermo O'Donnell (1999) nos apontam ao observar a relação de fracasso entre Estado de Direito e países em desenvolvimento. Com vistas ao Brasil e à América Latina, os autores observam os entraves oriundos de práticas de regimes autoritários que persistem na região.

No âmbito dos entraves administrativos, as dificuldades se perpetuam em dois planos, no sigilo formal e na ausência de transparência. Primeiro, os processos disciplinares que buscam a responsabilização dos policiais investigados correm sob sigilo, o que inviabiliza a produção de dados referentes à atuação daquele órgão, como por exemplo, tempo de duração dos processos, os argumentos mobilizados pela acusação e defesa, as consequências do processo para a progressão na carreira do policial envolvido, o número de arquivamentos dos procedimentos apuratórios e os índices de absolvições e condenações nessa esfera.

$E$, segundo, ainda em âmbito administrativo, inconvenientes como a produção e a divulgação não transparente de alguns dados é outro elemento, o que ocorre muitas vezes, "produz-se o dado, porém não se dá a 
ele muita visibilidade, tornando seu acesso dificultado até mesmo para pesquisadores mais experientes" (Nunes, 2014, p. 107).

Quando pensamos no acesso aos atores que operam a esfera administrativa, o desafio é superar o processo de desconfiança quanto aos pesquisadores externos à polícia, que pode estar atrelada a inúmeros fatores, conforme aponta Macedo, "os policiais exprimiriam uma desconfiança em relação às ciências humanas, à formação e aos outros de maneira geral (...)" (2015, p. 81). Vilma Reis (2005) também identifica esse problema ao observar a rejeição dos policiais durante a realização de entrevistas em sua pesquisa: "homens que têm rejeitado com veemência a presença do que eles chamam de policiólogos, 'pessoas que falam da polícia sem entender de polícia'” (p. 160).

No âmbito dos entraves judiciais a lista também é extensa. Vai desde a ausência generalizada de dados sistematizados a respeito de condenações, absolvições, pronúncias, impronúncias e desclassificações de réus nesses processos, a nível nacional, ao fato de muitos processos serem físicos, e, portanto, não estarem disponíveis nos portais digitais, ou ao fato de que, quando digitalizados, seu acesso ainda depende de uma senha cujo acesso é restrito aos advogados dos réus, membros do Ministério Público, familiares e demais pessoas autorizadas pelo Juízo, conforme determinação do Conselho Nacional de Justiça.

Ainda no âmbito judicial, estão as dificuldades de acompanhamento dos casos. Apenas os operadores que lidam diretamente com os processos oriundos de abordagens policiais que resultaram morte são capazes de identificar os processos nessa condição, pois não há indicadores ou marcadores que identifiquem rapidamente se o réu era policial e se estava ou não em serviço quando da ocasião do fato (Misse, 2013; Ferreira, 2017).

A lista de barreiras enfrentadas pelos pesquisadores e pesquisadoras que se interessam em desvendar as contradições da polícia que mata em serviço é extensa. Os obstáculos têm diferentes naturezas e encontram amparo tanto na esfera administrativa, quanto na judicial.

No fundo, esses desafios estão nos apontando para o problema da própria conformação do Estado democrático que se consolidou aqui no Brasil: "a elevada quantidade de mortes cometidas por policiais parece contrastar diretamente com a ideia de que o Brasil é um Estado Democrático de Direito" (Machado \& Ribeiro, 2016, p. 367).

\section{A chave não é única: as estratégias me- todológicas utilizadas pelos pesquisadores}

A complexidade do problema das mortes decorrentes de intervenção policial, e de seu respectivo tratamento no sistema de justiça, nos sinaliza a importância de olharmos o problema sob diferentes prismas. As pesquisas elaboradas nos últimos vinte anos nos mostram que são oriundas de áreas diversas, e que também - e consequentemente -, os desenhos da pesquisa, os métodos de coleta e análise de dados são bem diferentes.

Apesar das dificuldades de acesso ao campo, apontadas no item anterior, os pesquisadores têm se valido de variados mecanismos para produzir conhecimento acerca da polícia que mata. Essas estratégias metodológicas alcançam desde a concepção da pesquisa, o que engloba recorte, questões, objetivos e técnicas, à abordagem a ser adotada - quantitativa ou qualitativa, entre outras distinções. 
Neste contexto, e, a partir do material coletado nas pesquisas que foram produzidas nos últimos vinte anos, podemos inferir que os pesquisadores têm escolhido principalmente dois caminhos para estudar empiricamente o problema da letalidade policial: (I) estudar as abordagens policiais que resultam em morte em si, o que inclui o perfil dos autores e vítimas, consequências legais para os autores, índices nacionais, regionais e locais, representações do problema pela própria polícia e familiares das vítimas, dentre outros; (II) estudar o que o sistema de justiça tem feito para fazer frente ao problema da letalidade policial,,$^{13}$ o que inclui a responsabilização dos policiais envolvidos no fato em diferentes esferas do direito - administrativo, civil, criminal e internacional -, as representações do problema pelos atores do sistema de justiça criminal, isto é, juízes, promotores, defensores públicos, advogados, delegados, serventuários da justiça, assim como o desenrolar dos procedimentos e as prisões dos policiais envolvidos, só para citar alguns exemplos.

Por sua vez, essas estratégias podem ser organizadas em dois grandes grupos, em função da abordagem adotada e se referir mais diretamente às letras ou aos números. ${ }^{14}$ As primeiras, designadas de pesquisas de abordagem qualitativa, são aquelas que "se ancora[m] na dialética das representações, ações e interpretações dos atores sociais em relação ao seu meio" (Deslauriers \& Kérisit, 2010, p. 135). As pesquisas qualitativas, portanto, não dependem de quantificação estatística, mas da capturação e categorização dos fenômenos sociais e seus significados (Webley, 2010).

\footnotetext{
13 Supondo que as instituições e atores que atuam no sistema de justiça tenham alguma relevância na redução da letalidade policial. Álvaro Pires (2008) para fazer referência ao qualitativo e ao quantitativo.
}

Já as demais, as chamadas pesquisas de abordagem quantitativa, são as definidas por Lisa Webley como aquelas que se dedicam a questionar fatos observáveis, mensuráveis e independentes (Webley, 2010), são aquelas que consideram os elementos que podem ser quantificáveis e traduzidos em números, através do apelo a recursos estatísticos, como por exemplo análises de regressão, percentuais, desvio-padrão, cálculos de coeficiente de correlação.

As pesquisas e pesquisadores observados foram categorizados em função da abordagem adotada. Essa disposição das pesquisas/pesquisadores está elencada abaixo. Cabe frisar que nosso objetivo não foi marcar as diferenças entre as duas abordagens - até porque ambas tentam observar a realidade social, respondendo questões específicas-, mas, apenas mostrar que mesmo com questões diferentes no nível dos dados, quando buscam produzir generalizações sobre a vida social (Becker, 2014) trazem importantes contribuições para o estudo da polícia que mata.

\subsection{Abordagens qualitativas}

O primeiro grupo de pesquisadores e pesquisadoras é composto por aqueles e aquelas que decidiram olhar para o problema da letalidade policial e seu tratamento em âmbito judicial por meio de uma perspectiva qualitativa. Por muitos anos, a produção bibliográfica a respeito do tema foi elaborada a partir de uma perspectiva teórica, sem necessariamente estar baseada em métodos e técnicas de pesquisa empíricos, ainda que construída a partir de experiências do cotidiano. Neste contexto, cabe destacar a tradição de estudos produzidos por movimentos sociais, notadamente integrantes do Movimento Negro, sobretudo numa pers- 
pectiva de denúncia, intensificada na década de 1970.

A redemocratização do país em 1988 possibilitou o surgimento, e posterior, fortalecimento de suas instituições políticas, assim como, de instrumentos jurídicos de fiscalização e controle da informação e da performance de instituições públicas, em diversos âmbitos. Desde então, as pesquisas que buscaram compreender o fenômeno da letalidade policial ou seu tratamento pelo sistema de justiça, a partir de técnicas específicas de coleta de dados - muitas das quais se beneficiam do direito de acesso à informação, descrevem ou explicam os mecanismos internos às polícias e às instituições jurídicas que possibilitam a permanência do fenômeno.

Para os fins da presente pesquisa e em função dos critérios levantados na fase de seleção, nos deteremos sobre as seguintes pesquisas: Orlando Zaccone D'elia Filho (2013), na Ciência Política; Vilma Reis (2005), Michel Misse (2011) e Henrique de Linica Macedo (2015), na Sociologia; e Maíra Machado e Marta Machado (2015), no Direito.

Em 2005, no âmbito de uma pesquisa de mestrado, Vilma Reis partiu de uma perspectiva interseccional, para compreender as políticas de segurança pública implementadas nos bairros populares de Salvador e as representações dos seus gestores, durante os anos de 1991 a 2001. O objetivo do estudo foi propor uma análise acerca do modelo de ação policial desenvolvido pela Secretaria de Segurança Pública da Bahia e pelos Comandos das polícias, em relação aos bairros populares da referida cidade.

Do ponto de vista metodológico, a pesquisadora buscou, na observação participante - em formatura de oficiais, encontros pú- blicos com autoridades nacionais e locais e visitas às instituições - e na realização de entrevistas com atores-chave, como os gestores da Assessoria Geral da Secretaria de Segurança Pública, do Comando Geral da Polícia Militar do Estado da Bahia e da Corregedoria Geral da Polícia Militar do Estado da Bahia -, identificar como estes gestores do âmbito da segurança pública compreendiam suas próprias ações e a atuação das polícias, num contexto em que a capital baiana experimentara taxas elevadas de homicídios em geral, mas também de registros de "autos de resistência à prisão", e de prisões (Reis, 2005, p. 150).

O que eu fui buscar na fala e no silêncio dos meus informantes, foi o que eles pensam sobre eles mesmos, o que eles leram dos olhares de fora, especialmente as instituições de controle externo - Ministério Público, organizações sociais, já que a polícia é uma das instituições em confronto aberto com a população (Reis, 2005, p. 157)

Além da coleta de dados provenientes das duas técnicas já mencionadas, a pesquisadora também se vale de dados coletados em fontes documentais.

Ao abrir seu espectro de observação para os "homens de dentro" e para "o alto escalão" (Reis, 2005, p. 18) da polícia civil e da polícia militar do estado da Bahia, Reis acessa uma esfera institucional ainda pouco explorada. Como resultados, Vilma Reis constrói a categoria "jovens-homens-negros" (2005, p. 14) para se referir às dimensões identitárias da vitimização das políticas de segurança pública do período estudado; diagnostica a "baixa receptividade de oficiais a pesquisadores de fora da polícia" (Reis, 2005, p. 160); a distribuição racial e de gênero na esfera institucional observada, 
Há uma riqueza de informações nestas ante-salas dos coronéis onde poderes e sub -poderes circulam e fazem a vida girar. $\mathrm{Na}$ ante-sala sempre havia muitos/as negros/ as, mas ao adentrar os gabinetes, em geral, não me deparei com muitos negros, como é o desenho dos de média e baixa patente soldados, tenentes e sargentos, mas sim encontrei em geral com brancos e "brancos baianos" (Reis, 2005, p. 163).

O recorte interseccional dado à pesquisa por Vilma Reis, através dos dados coletados, permitiu que a pesquisadora afirmasse que os lugares ocupados na hierarquia daquelas instituições estavam relacionados às categorias gênero, raça e geração, de modo a privilegiar homens, brancos, com idade acima de 40 anos (Reis, 2005).

Quanto às percepções dos gestores sobre as políticas de segurança e seus impactos, Vilma Reis (2005) observa nas entrevistas que cada gestor tem uma concepção própria de segurança pública decorrente de divisões de cunho ideológico, geracional e a aspectos relacionados à influência da instituição de origem do entrevistado. Reis (2005) também identifica um silenciamento nos discursos no que diz respeito à motivação racial em relação à atuação violenta da polícia.

A pesquisa realizada por Vilma Reis (2005), portanto, aporta importantes elementos metodológicos para o campo de estudos sobre a polícia que mata, na medida em que nos ajuda a compreender a importância de olharmos para além da atuação policial individual. A referida pesquisa nos faz ampliar o escopo de observação e incluir como objeto de pesquisa gestores responsáveis (in) diretamente, atores institucionais e outros agentes da esfera administrativa que operacionalizam as políticas de segurança pública. Ademais, ela nos mostra como a atuação política é um ajuste importante nas lentes do pesquisador e da pesquisadora.
Outro trabalho que traz importantes contribuições de cunho metodológico foi realizado por Michel Misse (2011) e sua equipe. Os pesquisadores tinham por objetivo compreender "como são realizados os procedimentos apuratórios e o julgamento de casos chamados de "autos de resistência", na cidade do Rio de Janeiro" (Misse, 2011, p. 10), por meio de uma perspectiva sociológica empírica.

Na observação do desenho da referida pesquisa, dois elementos chamam atenção: (i) o fato dela ter se originado da agenda de pesquisa criada por uma pesquisa anterior, de 2008, sobre o inquérito policial no Brasil, o que facilitou a entrada dos pesquisadores no campo para a pesquisa que estamos observando - esse fato nos coloca diante da importância de estudar a polícia de forma contínua e complementar; (ii) a ambição dos objetivos específicos que buscavam, dentre outros, "Entender como a Polícia Civil realiza o trabalho de investigação, através de inquéritos policiais, dos casos de "auto de resistência", em delegacias distritais "; "Descrever e analisar os critérios que orientam o trabalho realizado em Promotorias de Investigação Penal, da $1^{a}$ Central de Inquéritos do Ministério Público do Estado do Rio de Janeiro, nos inquéritos de "auto de resistência"" (Misse, 2011, p. 12). Cabe destacar que a referida pesquisa foi financiada pelo ConseIho Nacional de Desenvolvimento Científico e Tecnológico e que foi desenvolvida por uma equipe de oito pesquisadores.

Metodologicamente, a etnometodologia foi adotada para analisar as práticas rotineiras relativas ao processamento legal dos casos de "auto de resistência" (Misse, 2011). Assim, o que estava sendo observado eram os elementos utilizados pelos operadores do Sistema de Justiça para selecionar o que "é 
plausível e razoável, de acordo com um saber comum sobre a prática policial e sobre o contexto dos homicídios que dela decorrem" (Misse, 2011, p. 19).

A pesquisa, conforme destacado pelos autores, é predominantemente qualitativa, mas uma importante fase da mesma buscou analisar quantitativamente o fluxo dos procedimentos no Sistema de Justiça Criminal (Misse, 2011). Este cruzamento de abordagens qualitativas e quantitativas nos mostra que há mais um caráter de complementariedade do que de oposição ou disputa entre as referidas abordagens.

Quanto à operacionalização e execução da pesquisa, observa-se que o corpus empírico é bastante amplo:

pesquisadores passaram a acompanhar sistematicamente o trabalho de promotores da la Central de Inquéritos nesses casos, analisando qualitativamente os inquéritos e realizando entrevistas com os promotores. Também foi feita a observação do trabalho de investigação policial em homicídios em outra delegacia da Zona Norte da cidade, por uma nova equipe de pesquisa. Além disso, entre janeiro de 2010 e dezembro de 2011, foram acompanhados casos denunciados no Tribunal de Justiça (TJ), nas quatro varas dos tribunais do júri, com assistência a audiências, entrevistas com juízes, promotores, defensores, e familiares de vítimas, e leitura dos processos. Foram feitas, ainda, entrevistas com policiais $\mathrm{mi}$ litares e civis (Misse, 2011, p. 14).

Ao se depararem com as dificuldades reais de acesso a dados nesse campo, conforme apontamos em item anterior, os pesquisadores utilizaram uma estratégia interessante: ao ter acesso a alguns casos, eles usaram o contato com servidores das varas para ter conhecimento de outros casos, o que dobrou a amostra com a qual sua equipe pretendia trabalhar.

O trabalho de pesquisa nas quatro varas do Tribunal do júri, entre janeiro de 2010 e dezembro de 2011, teve início a partir desses 13 casos denunciados e, ao longo do contato com os operadores, ficamos sabendo de outros que estavam tramitando, chegamos assim a acompanhar o julgamento de 26 casos, sendo 13 deles originários das denúncias conjuntas feitas por um promotor, em julho de 2009, e os demais indicados por defensores, promotores e juízes das varas, ou foram por nós encontrados na análise de outros processos ou na assistência a audiências (Misse, 2011, p. 16).

A referida pesquisa revelou que há, além de uma baixa qualidade dos inquéritos instaurados para a investigação dos chamados "autos de resistência", uma precariedade dos elementos probatórios que poderiam afirmar ou negar a legítima defesa dos policiais que atuaram em tais ocorrência. Identificaram também uma tendência de arquivamento dos inquéritos instaurados e o fato rotineiro de não haver questionamentos por parte da Polícia Civil a respeito das versões fornecidas pelos policiais autores do fato (Misse, 2011).

A diversidade de métodos para estudar a polícia que mata ou seu tratamento transcende as barreiras disciplinares. Orlando Zaccone D'elia Filho (2013) também se dedicou ao tema, a partir de uma outra perspectiva teórica e metodológica. Apesar de inscrito na Ciência Política quando da realização da referida pesquisa, ${ }^{15}$ a estratégia adotada por esse autor contou com sua experiência como Delegado de Polícia no Rio de Janeiro, o que conferiu a sua pesquisa um aporte a partir de sua condição de operador direto do sistema de justiça criminal.

Em sua pesquisa qualitativa, Zaccone (2013) analisou 314 inquéritos de autos de resistên-

15 Até a data de conclusão deste texto, a tese do referido autor não estava disponível no acervo digital do Departamento de Ciência Política da Universidade Federal Fluminense, instituição na qual a pesquisa foi desenvolvida, por isso, nossa pesquisa realizou-se a partir do ivro "Indignos de vida: a forma jurídica da política de extermínio de inimigos na cidade do Rio de Janeiro", editado pela Revan, no ano de 2015, o qual se refere a sua tese de doutoramento em Ciência Política e leva o mesmo título. 
cia, referentes ao período de 2003 a 2009, instaurados entre os anos da pesquisa e arquivados a pedido do Ministério Público, todos homologados pela justiça do Rio de Janeiro.

O autor buscou observar os elementos que serviriam aos operadores do direito para a construção da decisão de legitimidade das ações policiais que resultaram morte, isto é, entender o que havia motivado o Ministério Púbico do Rio de Janeiro a requerer o arquivamento dos inquéritos policiais provenientes de autos de resistência naquele estado (Zaccone, 2015). Para tanto, ele partiu da seguinte questão: "em que condições se habilita o uso da força policial ao patamar de massacre, ou seja, quais instrumentos ensejam qualificar a força letal e rotineira das polícias na cidade do Rio de Janeiro como uso legal da força"? (Zaccone, 2015, p. 23).

A pesquisa construída por Zaccone (2015) nos chama atenção porque, tendo em conta sua posição estratégica de pesquisador e Delegado de Polícia, ela nos permite observar as razões que levam o Estado - na figura do Ministério Público - a pedir o arquivamento de determinado procedimento em detrimento de outro que teve, a princípio, ações policiais com as mesmas características e que ensejaram, segundo o autor, altos índices de letalidade do sistema penal brasileiro, com destaque para aqueles praticados rotineiramente nas favelas.

Dentre os resultados apontados por Zaccone (2015), que merecem destaque estão o fato que em centenas de promoções de arquivamento, analisadas na pesquisa, a definição da presença do "inimigo" em territórios segregados garante a legitimação das mortes produzidas a partir de ações policiais.
Quase nada é falado sobre o momento da ação que resultou na morte a ser investigada. Muito pelo contrário, é possível observarmos modelos de arquivamento utilizados por promotores de justiça criminal em diferentes inquéritos, bem como modelos utilizados por diferentes promotores de justiça, revelando uma padronização da produção de subjetividades na legitimação das mortes produzidas pelo sistema penal (Zaccone, 2015, p. 155).

Ou ainda, o fato de haver modelos de promoção de arquivamento utilizados em dezenas de procedimentos pelo mesmo promotor de justiça, como uma espécie de receita pronta, que estabelece padrões para que um "fato descrito como homicídio deixe de ser um crime, sendo legitimado pela condição do morto; pela localidade onde ocorreu a ação policial que resultou a morte; e pela apreensão de armas e drogas" (Zaccone, 2015, p. 157).

No registro das pesquisas qualitativas, cabe ainda destacar o trabalho coordenado por Maíra Rocha Machado e Marta Rodriguez de Assis Machado (2015) ao se debruçarem sobre o Massacre do Carandiru, ${ }^{16}$ no campo do Direito. As pesquisadoras partiram de um caso emblemático de uma ação policial letal para "avaliar como as instituições do sistema de justiça brasileiro reagiram a um episódio de grave violação de direitos humanos ocorrido no período de nossa transição à democracia" (2015, p. 19). O pano de fundo da referida pesquisa foi compreender os "mecanismos de responsabilização individual e estatal, iniciados por diferentes autoridades após a ocorrência do Massacre do Carandiru" (2015, p. 45).

Diferentemente da pesquisa coordenada por Misse (2011) que se desenrolou em torno

16 Fato ocorrido em 2 de outubro de 1992, após uma intervenção da Polícia Militar do Estado de São Paulo, na Casa de Detenção de São Paulo. A ação provocou a morte de pelo menos 111 detentos, e deixou inúmeros feridos. Para saber mais: https://massacrecarandiru.org.br/ 
de 26 casos, por meio de etnometodologia, o trabalho desenvolvido por Maíra Machado e Marta Machado (2015) faz uso do estudo de caso único como estratégia de coleta e análise dos dados.

O estudo de caso realizado pelas pesquisadoras permitiu a concentração da coleta de dados em torno de um único evento - o massacre do Carandiru. Elas trabalharam sobre processos criminais, ações de indenização movidas por familiares, em âmbito civil, e em processos administrativos e administrativo-disciplinares, além de documentos que envolvem o processo internacional que tramitou perante o Sistema Interamericano de Direitos Humanos (Machado \& Machado, 2015, p. 24).

Com essa entrada estratégica e pontual sobre o campo, as pesquisadoras conseguiram relatar, de forma minuciosa, como e em que circunstâncias se deu a atuação de diferentes instituições, nas diversas instâncias e graus de jurisdição do sistema de justiça para que ocorresse, ou não, a responsabilização disciplinar, criminal, civil e internacional dos policiais e autoridades envolvidas na ocorrência do massacre.

Movimento semelhante foi feito por Henrique de Linica dos Santos Macedo (2015) ao realizar um estudo a partir de dois casos emblemáticos, em sua dissertação de mestrado em Sociologia. Macedo escolheu para o estudo dois casos de suposto confronto entre policiais e "sujeitos incriminados" (2015, p. 97) que ocorreram no interior do estado de São Paulo. O primeiro ocorreu no município de Itatiba, no qual três pessoas morreram em uma ação da Rondas Ostensivas Tobias de Aguiar em maio de 2011 e, o outro, na cidade de Várzea Paulista, no qual nove pessoas morreram em outra ação do mesmo grupo policial, em setembro de 2012. Segundo o pesquisador, "estes não são casos isolados, o recorte pretendido nesta dissertação visa delimitar as ações da ROTA no período de maio de 2011 e setembro de 2012" (Macedo, 2015, p. 15).

Diferentemente da pesquisa realizada por Maíra Machado e Marta Machado (2015), Macedo (2015) utiliza os casos para ter acesso a discursos e práticas produzidos pelas ROTA, em recortes temporais específicos.

Ao apresentar seus mecanismos de acesso ao caso, o pesquisador deixa claro sua posição privilegiada de ser filho ${ }^{17}$ de policial militar: "no nosso caso, na iniciação cientifica e na pesquisa de mestrado, o acesso ao batalhão entre 2011 e 2012 foi possibilitado por oficiais de alta patente aposentados da PMESP. Estes oficiais, contudo, faziam parte do convívio familiar do pesquisador" (Macedo, 2015, p. 13).

Conforme explica o pesquisador em seu texto, o fato de ser filho de policial e de ter tido acesso privilegiado a alguns elementos de seu objeto, também lhe conferiu um ônus, pois o uso de relações pessoais como estratégia de acesso ao campo tornou-se obstáculo, dada a necessidade de anonimização dos participantes e da inevitável e paradoxal exposição dos policiais participantes da pesquisa (Macedo, 2015). Diante desse desafio, o pesquisador passou a buscar informações públicas ou que foram publicizadas através da imprensa.

Falas que, ao serem proferidas e publicadas por esses veículos de imprensa, permitem a sua enunciação sem qualquer problema de ordem ética. E quando utilizarmos a fala de algum interlocutor, o manteremos em sigilo, sem maiores

17 "O interesse pelo tema vincula-se à nossa própria trajetória. Primeiro por ser filho de um policial militar, que cresceu ouvindo e vivenciando fatos pelas poucas histórias contadas pelo meu pai" (p. 04) 
informações, por questões éticas, pois dado as circunstâncias da realização da pesquisa, ficamos com a série discursiva, dando ênfase ao seu conteúdo (Macedo, 2015, p. 38).

Neste sentido, o autor buscou fazer análise de conteúdo de enunciados, e coleta de documentos produzidos sobre os casos estudados, como Boletins de Ocorrência (B.O) e Inquéritos Policiais (IP), além de dissertações e teses profissionais frutos de pesquisas realizadas pelos próprios oficiais da Polícia Militar do Estado de São Paulo.

Dessa forma, foram analisados documentos como os inquéritos policiais e processos judiciais instaurados para a apuração dos casos aqui analisados, (...) com ênfase no esforço de analisar e identificar, de forma mais ampla, como essa administração estatal de conflitos por meio da gestão da segurança pública no Estado de São Paulo foi realizada. Também buscamos matérias jornalísticas, textos de blogs (policiais e outros) e páginas de policiais nas redes sociais, com destaque para os de policiais e ex -policiais da ROTA. Nessa estratégia vale ressaltar que os autos dos processos puderam ser acessados e estudados pelo pesquisador pelo acesso dos mesmos na Ouvidoria das Polícias do Estado de São Paulo, que acompanha o andamento dos processos que a ela foram denunciados ou foram abertos por iniciativa própria. Quanto às matérias jornalísticas foram reunidas informações sobre os casos e os contextos em que estes estavam inseridos, destacando-se um número maior de matérias no período de 2012 pela natureza dos eventos daquele ano (Macedo, 2015, p.39).

A análise do material coletado é feita a partir da hipótese de que há nas políticas públicas do âmbito da segurança pública o que o autor chamou de "uma estruturação opaca do conflito" (Macedo, 2015, p. 123), isto é, as formas eleitas pelo Estado para gerir conflitos priorizam estratégias militarizadas no controle ao "crime organizado". Segundo o autor, essas estratégias privilegiam "uma política de segurança pública baseada na opacidade, no sigilo e na gestão do fluxo de informações" (Macedo, 2015, p. 124), além dela mesmo ser produtora, se apropriar e utilizar a violência como ferramenta para a realização de seu trabalho (Macedo, 2015).

A pesquisa realizada por Macedo (2015) concluiu que há um padrão nos discursos analisados, os quais "não são só enunciados e verbalizados, são antes uma linguagem política enunciada por práticas" (p. 177). O autor identifica a violência marcada nos enunciados como algo que integra a estratégia militarizada de controle do crime e que, portanto, é característica do modelo político-ideológico e da "ética policial" (Macedo, 2015).

\subsection{Abordagens quantitativas}

O segundo grupo de pesquisadores é composto por aqueles que elegeram os números para reconstruir a letalidade das ações policiais, ou para explicar os efeitos de alguma variável sobre o referido fenômeno. Aqui encontram-se as pesquisas quantitativas, cujo objetivo de forma geral foi estabelecer uma relação entre frequência e relevância dos elementos que compõem o quadro mais amplo por eles desenhados. O primeiro deles é o estudo coordenado por Ignácio Cano (2013), no campo da Sociologia, onde - pesquisador buscou monitorar mensalmente um conjunto de indicadores que permitiram o acompanhamento e a evolução de delitos violentos no Rio de Janeiro. Inicialmente, sua preocupação centra-se em três categorias de delitos: as mortes violentas intencionais, os crimes violentos não letais contra a pessoa e os crimes violentos contra o patrimônio.

Do ponto de vista metodológico, Cano (2013) utilizou indicadores que se basearam exclusivamente em registros policiais, especificamente, nos Registros de Ocorrência (R.O.) 
da Polícia Civil, divulgados no Diário Oficial. Os dados foram coletados na página do Instituto de Segurança Pública do Estado do Rio de Janeiro. "Para o cálculo das Taxas por 100 mil habitantes, são utilizadas estimativas elaboradas com base no Censo de 2000 e 2010, e no Censo de 2010 do IBGE" (Cano, 2013, p. 3).

Nesse estudo quantitativo em que Cano (2013) buscou observar a abrangência dos crimes violentos na capital e em algumas cidades do interior do Rio de Janeiro, entre os anos de 2011 a 2013, ele pontua que "além de apresentarem taxas bem menores em relação aos demais tipos de delito, os registros de Autos de Resistência apresentam também outras características que o diferem dos demais crimes relacionados no grupo "Mortes Violentas Intencionais'" (2013, p. 11), como o fato de ter havido um decréscimo significativo das taxas mensais a partir de 2007 em todas as regiões do Estado do Rio de Janeiro, quando comparado aos demais crimes deste grupo.

Vale um destaque. Em pesquisa anterior, Cano (1999) buscara identificar um viés racial no uso da força letal pela polícia no Brasil. ${ }^{18} \mathrm{~A}$ pesquisa construiu "um teste para a hipótese segundo a qual a polícia discrimina minorias raciais, notadamente os negros" (Cano, 2014, p. 4). Porém, dadas as dificuldades apontadas pelo pesquisador, no sentido de que à época não havia dados sistemáticos disponíveis sobre abordagem policial e raça, a pergunta foi reelaborada e passou-se a questionar: "a polícia mata mais negros do que brancos em circunstâncias comparáveis?".

Do ponto de vista metodológico, essa pesquisa quantitativa desenvolveu-se em São Paulo e no Rio de Janeiro.

\footnotetext{
8 Trabalharemos com a versão da referida pesquisa publicada e traduzida em 2014
}

Em São Paulo seguiu-se uma estratégia dupla. Primeiro, a equipe de pesquisa examinou os arquivos de quatro dos cinco Tribunais do Júri da cidade de São Paulo. Os livros-tombo de cada Tribunal foram analisados, a fim de encontrar os casos de homicídio envolvendo policiais no exercício da profissão e fora dele. A pesquisa contemplou casos que aconteceram entre janeiro de 1996 e julho de 1999 (...). No total, foram coletadas informações de 215 casos de homicídio doloso de civis cometidos por policiais na cidade de São Paulo (...). Tanto no Rio de Janeiro quanto em São Paulo a raça das vítimas foi relatada em diversos documentos, mas será analisada a partir do Boletim ou Registro de Ocorrência, considerandose que este documento é mais comum. Além disso, ele reflete a categorização racial feita pelos próprios policiais no momento mais próximo ao da intervenção. (Cano, 2014, p. 12).

Concluída a coleta dos dados referentes à cor das vítimas, os dados foram sistematizados em tabelas e submetidos a equações matemáticas do tipo modelo log-linear, probabilidade, dentre outros. Ao apresentar suas conclusões, Cano (2014) sinaliza as limitações da estratégia metodológica adotada:

Tanto no Rio de Janeiro quanto em São Paulo existe uma clara disparidade racial entre as vítimas fatais nas intervenções da polícia, quando comparadas com a população carcerária e com a população geral. Contudo, esta disparidade não significa necessariamente que existe um viés racial na atuação dos policiais, já que os dados sofrem de diversas limitações e outras hipóteses alternativas poderiam também explicar os mesmos resultados. Por exemplo, a categorização das raças foi colhida a partir de fontes diversas (pela polícia ou pelos agentes prisionais, por um lado, ou pelos próprios cidadãos no Censo, por outro) e, assim, podem não ser diretamente comparáveis. Mais importante ainda, para demonstrar o viés a partir desses dados, teríamos que presumir que todos os grupos raciais se engajam em crimes violentos e em conflitos armados com a polícia no mesmo grau. Junte-se a isso a questão que a alta proporção de pretos entre as vítimas fatais poderia ser também explicada pelo fato de terem muita representatividade nas favelas, ou seja, nas áreas onde as inter- 
venções policiais são mais letais. Dessa forma, os dados poderiam ser interpretados a partir de um viés geográfico, e não a partir da discriminação racial da polícia (Cano, 2014, p. 15).

Ainda numa perspectiva quantitativa, Jacqueline Sinhoretto (2014) e sua equipe buscaram investigar a existência de mecanismos de produção da desigualdade racial na atividade policial, sobretudo nas ações letais, em São Paulo. Diante da ausência de dados públicos sobre letalidade policial e a cor/raça dos indivíduos mortos pela ação da polícia, as pesquisadoras buscaram reconstruir essas informações através de dados coletados nos casos autuados na Ouvidoria da Polícia do Estado de São Paulo sobre mortes provocadas por policiais, nos anos 2009 a 2011, o que permitiu a produção de uma base de dados sobre a letalidade policial e o perfil das vítimas e dos policiais envolvidos (Sinhoretto et al, 2014).

Os 734 procedimentos analisados pelas pesquisadoras eram compostos em sua maioria de "documentos oficiais como Boletim de Ocorrência, Inquérito Policial Civil ou Militar, laudos necroscópicos, entre outros, que em geral trazem informação sobre a cor/raça da vítima do homicídio" (Sinhoretto et al., 2014, p. 7). Por isso, a quantidade de dados a serem coletados demandou o uso de instrumentos técnicos pelas pesquisadoras. Essa tarefa foi desenvolvida por softwares de coleta, gestão e tratamento de dados.

O instrumento de coleta das informações nos autos foi desenvolvido para o software de pesquisa Sphinx e aplicado à totalidade dos casos de 2009 a 2011 disponibilizados pela Ouvidoria. Importante destacar que a coleta não foi feita na totalidade dos casos registrados pela Ouvidoria, sob a justificativa de que alguns deles estavam em trânsito e indisponíveis para consulta. Assim, a coleta foi realizada junto aos casos disponibilizados. Ao final da coleta, a base de dados foi tratada com a ajuda do pacote estatístico SPSS Statistics (Sinhoretto et al., 2014, p. 15).
A pesquisa aponta que o perfil das vítimas é composto, predominantemente, por pessoas "negras (61\%), homens (97\%) e jovens, entre 15 e 29 anos de idade" (Sinhoretto et al., 2014, p. 10), o que não difere do perfil das vítimas de homicídios em geral, "jovens-homens-negros" (Reis, 2005; Flauzina, 2006; Alves, 2011).

Os dados indicam que há maior letalidade policial sobre a população negra. Ao calcularmos as taxas de mortos por 100 mil habitantes, dentro de cada grupo de cor/raça, no ano de 2011, é possível observar que são mortos três vezes mais negros do que brancos.

Quanto ao perfil dos autores, a pesquisa constatou que a "maioria deles é de cor branca (79\%), é homem (97\%) e se concentra na faixa etária de 25 a 39 anos (73\%)" (Sinhoretto et al., 2014, p. 16).

Por fim, está a pesquisa desenvolvida por Ludmila Mendonça Lopes Ribeiro e Igor Suzano Machado (2016), onde os pesquisadores buscaram observar o funcionamento do sistema de justiça criminal a partir de "processos de homicídio intencional envolvendo policiais como autores dos crimes" (p. 366). O objetivo da pesquisa foi observar o tempo de processamento deste tipo de processo (Machado \& Ribeiro, 2016). A amostra representativa do universo de processos sobre tais ocorrências que passaram pelo sistema de justiça criminal foi definida em cinco cidades brasileiras: Belém, Belo Horizonte, Goiânia, Recife e Porto Alegre, locais onde foram identificadas elevadas taxas dentre as regiões administrativas do Brasil de que são parte, especificamente no ano de 2013. O recorte espacial dado à pesquisa, através da construção dessas escolhas permitiu ter uma "amostra do que acontece no país como um todo, o que não seria possível a partir da análise de casos de apenas uma cidade ou região" (Machado \& Ribeiro, 2016, p. 371). 
Ainda no que concerne aos esclarecimentos metodológicos,

\begin{abstract}
os autos judiciais foram escolhidos como fonte de informação por condensarem todas as narrativas das instituições que compõem o sistema de justiça criminal sobre o crime, o criminoso e a vítima, assegurando que as diferentes formas de pronunciamento do estado diante daquela morte seriam contempladas na análise (...)

(Machado \& Ribeiro, 2016, p. 371).
\end{abstract}

Cabe frisar que os casos em que os policiais figuram como autores são diversos, e que, no total de 786 processos estão "desde os confrontos que caracterizam os autos de resistência previstos no art. 292 do CPP, até os conflitos de proximidade, como os decorrentes de brigas entre conhecidos e casos amorosos" (Machado \& Ribeiro, 2016, p. 374).

A forma que os pesquisadores encontraram para calcular a manifestação da seletividade foi calcular "o tempo de processamento de cada caso, considerando o lapso temporal transcorrido entre a data do crime e a data em que o processo se encerrou" (Machado \& Ribeiro, 2016, p. 379), esse raciocínio também foi aplicado para o cálculo, por exemplo, das condenações, absolvições, pronúncias e impronúncias, tempo médio de percurso dos processos, dentre outros elementos. Nesse sentido, os autores trabalharam com as seguintes categorias: "homicídios interpessoais", "homicídios relacionados a atividades criminais", "homicídios decorrentes de vingança", "homicídios mal definidos", "homicídios decorrentes de confronto policial", "outros homicídios envolvendo policiais", "homicídios de proximidade envolvendo policiais".

Não obstante as dificuldades proporcionadas por essa categorização - relatadas pelos pesquisadores, apresentaremos abaixo apenas os dados relativos aos "homicídios de confronto policial", dados os objetivos desse texto, que consiste, apenas para relembrar, nas estratégias metodológicas encontradas pelos pesquisadores para estudar a polícia que mata em serviço.

O trabalho traz conclusões interessantes acerca do percurso e do desfecho dos processos que tiveram como origem "homicídios decorrentes de confronto policial". A primeira delas diz respeito à decisão de primeira instância. Dos 28 processos que compõe esta categoria, 64,3\% alcançaram a fase de pronúncia, 21,4\% impronunciados, 14,3\% absolvidos sumariamente, e 0,0\% foram desclassificados e extintos.

A pesquisa revelou também que $44,4 \%$ dos processos que chegaram ao tribunal do júri foram absolvidos e 33,3\% foram condenados, $11,1 \%$ foram desclassificados, os demais tiveram outro destino (Machado \& Ribeiro, 2016, p. 377). Quanto ao tempo de duração entre a data do crime e a data em que o processo foi encerrado, vale a pena fazer uma comparação com a categoria "homicídios interpessoais" em que havia policiais envolvidos como autores do crime e os "homicídios decorrentes de confronto policial". Na primeira, os processos levaram, em média, 3.111 dias entre as duas datas, enquanto na segunda foram 2.517 dias entre a data do crime e a data de encerramento dos processos.

Esse dado surpreende o senso comum construído entorno desses casos, segundo o qual os processos originados com "homicídios decorrentes de confronto policial" percorriam o fluxo da justiça criminal num tempo maior quando comparados aos demais homicídios em que os réus não são policiais em serviço. Segundo os pesquisadores, "os homicídios envolvendo policiais não duraram mais de 20 anos e, por isso, não alcan- 
çaram a prescrição, o que rechaça a ideia de que esses casos seriam invalidados pelo simples decurso do tempo" (Machado \& Ribeiro, 2016, p. 380).

Como se viu, a abordagem quantitativa tem suas limitações, ela não permite um aprofundamento dos "como", nem dos "porquês", mas facilita a observação de um quadro geral construído com base em frequências e rotinas. Nesse contexto, as pesquisas quantitativas observadas garantiram uma organização daquilo que estava pulverizado, e, portanto, ininteligível.

As dificuldades encontradas pelos pesquisadores dedicados à polícia que mata estão sendo enfrentadas das mais variadas formas, como não poderia deixar de ser dada a complexidade do objeto. Ao colocar em diálogo alguns desses pesquisadores, foi possível acessar o problema de diferentes ângulos, perspectivas, lugares, posições políticas, temporalidades e referenciais teóricos.

Diante deste panorama, com base nas pesquisas observadas, é possível inferir que, apesar das dificuldades de acessar os atores e instituições que compõe o quadro mais amplo a respeito da polícia que mata em serviço, os pesquisadores e pesquisadoras, de diferentes áreas, têm demonstrado que, com diferentes estratégias metodológicas é possível vencer parte das barreiras impostas pelo sistema de justiça, que não permite ou inviabiliza a produção de conhecimento na área.

Dentro deste contexto, observa-se que há importantes diagnósticos a respeito da atuação das instituições do sistema de justiça criminal, de forma individual e coletiva, mas também sistêmica, além de um acúmulo de práticas para a operacionalização das pesquisas e o recorrente compartilhamento de matérias pelos pesquisadores, a exemplo do acervo documental elaborado por Vilma Reis (2005); da plataforma digital em memória do massacre do Carandiru e de outras manifestações de violência estatal em instituições prisionais, alimentada em parte pelos dados levantados pela pesquisa "Carandiru não é coisa do passado" (Machado \& Machado, 2015) e a disponibilização de banco de dados do Tribunal de Justiça do Estado do Rio de Janeiro contendo uma lista de inquéritos e flagrantes tombados por aquele tribunal em determinado período de tempo, pelo pesquisador Ignácio Cano à pesquisa desenvolvida por Michel Misse (2011), o que viabilizou a execução da referida pesquisa.

No entanto, ainda se nota que, apesar da elaboração e execução das pesquisas demandarem conhecimento interdisciplinar, isto é, que os pesquisadores e pesquisadoras tenham no mínimo noções e domínio de métodos de pesquisas ligados à Sociologia, à Antropologia, à Direito, à Estatística e à Ciência Política, as articulações no plano teórico ainda são baixas, ou seja, o aprofundamento de hipóteses e teorias construídas por uma pesquisadora ou pesquisador é pouco trabalhado ou desenvolvido pelos demais. A consequência desse diagnóstico é a criação de agendas de pesquisa que não dialogam umas com as outras, não se complementam e aprofundam o conhecimento produzido a passos lentos.

No mais, estas pesquisas têm contribuído para a construção de um saber específico sobre a atuação letal da polícia e suas formas de responsabilização, o que nos leva a refletir sobre o papel político que os pesquisadores acabam exercendo quando se dedicam a este tema.

Ao discutir as dificuldades de implementação do Estado de Direito no Brasil, e nos 
demais países da América Latina, tendo em vista a exclusão social e econômica oriunda de níveis persistentes de desigualdade, Oscar Vieira (2007) nos sinaliza a importância política daqueles que desafiam o sistema e são demonizados - como suspeitos, criminosos comuns, presos e mesmo membros de movimentos sociais. Nesse contexto, quando observamos as barreiras apontadas por pesquisadores do campo e suas respectivas estratégias de atuação, podemos afirmar que estes estão, assim como os demonizados apresentados por Vieira, desafiando "os sistemas formais de Estado de Direito a se tornarem mais imparciais" (2007, p. 48), transparentes e capazes de implementar leis para garantir a proteção de direitos humanos.

\section{Considerações Finais}

Neste texto apresentamos uma discussão a respeito de como as pesquisadoras e pesquisadores tem buscado, a partir da produção de pesquisa empírica, observar as instituições do Estado Democrático de Direito na consolidação dos direitos humanos.

A forma segundo a qual as pesquisadoras e pesquisadores têm reconstruído o problema da letalidade policial no campo da produção de conhecimento sinaliza quão grave é esse problema, que tem diferentes dimensões e que revela, por ser apenas um sintoma, a fragilidade de nossa democracia.

Salientamos que a própria complexidade do problema da letalidade policial - que atinge um patamar onde relações raciais, sociais e econômicas do país estão intrínseca e explicitamente ligadas - exige que pesquisadoras e pesquisadores busquem estratégias que rompam com as formas tradicionais de fazer pesquisa no campo do direito.

Por isso, num primeiro momento demarca- mos os desafios do campo e num segundo momento apresentamos os instrumentos e as estratégias adotados pelos pesquisadores.

A construção e consolidação do Estado Democrático de Direito Brasileiro depende da reconstrução diária de atores e de práticas institucionais que coloquem as alterações propostas pela constituição de 1988 num patamar substancial, isto é, os valores consubstanciados na nova ordem constitucional saiam do "papel".

No campo da segurança pública, um dos maiores desafios para implementação do Estado Democrático de Direito tem sido a atuação das polícias no Brasil (Pinheiro, 1997). Em meio a discursos que exigem a redução de crimes como roubos, latrocínios, corrupção na administração pública e tráfico de drogas, estão aqueles que silenciam as elevadas taxas de mortes decorrentes de intervenção policial.

Apesar do silenciamento promovido por alguns setores da sociedade civil e pelo próprio Estado, a letalidade das ações policiais tem mobilizado não só movimentos sociais comprometidos com a redução de tais números, mas também, pesquisadores de diferentes áreas.

Da Sociologia ao Direito, passando pela Antropologia e pela Criminologia, os pesquisadores têm buscado desvendar, a duras penas, o que chamamos de Caixa de Pandora, que nada mais é que o conjunto dos mecanismos ou barreiras que encobrem ou dificultam o estudo da polícia que mata em serviço.

A ausência de informações públicas ou publicizadas, a falta de transparência na produção e sistematização de dados fundamentais para a produção de políticas pú- 
blicas para enfrentar o problema e a falta de acesso a atores e instituições têm sido os principais desafios encontrados pelos pesquisadores e pesquisadoras.

Coube a este artigo apresentar, de forma breve, alguns exemplos de pesquisadores que toparam o desafio de desvendar Caixa de Pandora. Aqui, apresentamos os métodos e técnicas que têm sido adotados para problematizar, descrever, narrar e compreender os números e as representações a respeito da polícia que mata em serviço.

Esperamos ter contribuído para que os pesquisadores e pesquisadoras que estão pensando em enfrentar este emaranhado de desafios e dificuldades percebam que, apesar de haver muito trabalho pela frente, há também inúmeras formas e caminhos que já foram desenhados e que contribuem para que todos e todas avancemos no enfrentamento às diferentes formas de violência produzidas pelo Estado Brasileiro.

\section{REFERÊNCIAS BILIOGRÁFICAS}

Abdo, H. (2011). Mídia e processo. São Paulo: Saraiva. Assis, J. C. (2002). Lições de Direito para a atividade policial militar. 5 ed. Curitiba: Juruá.

Becker, H. S. (2014). A epistemologia da pesquisa qualitativa. Revista de Estudos Empíricos em Direito, vol. 1, n. 2, jul. 2014, p. 184-198.

Bueno, S., Cerqueira, D., \& Lima, R. S. (2013). Sob fogo cruzado II: letalidade da ação policial. In. Fórum Brasileiro De Segurança Pública. Anuário Brasileiro de Segurança Pública, ano 7, p. 118-127.

Campenhoudt, L. V., \& Quivy, R. (2008). Manual de Investigação em Ciências Sociais. Lisboa: Gradiva.

Cano, I. (2013). Boletim de criminalidade: abril de 2013. Laboratório de Análise da Violência: Universidade do Estado do Rio de Janeiro. Disponível em: http://www. lav.uerj.br/docs/bol/lavbolabril2013.pdf

Cano, I. (2014). Viés racial no uso da força letal pela polícia no Brasil. Tradução: Lígia Bastos Lages. Disponível em: https://aplicacao.mpmg.mp.br/xmlui/ bitstream/handle/123456789/1206/5\%25252520-

25252520 vies \% $25252520 \mathrm{ra}$ cial\%25252520\%25252520ignacio\%25252520cano.pdf? sequence $=1$

Cerqueira, D. (2013). Mapa dos homicídios ocultos no Brasil. Brasília: Ipea.

Costa, I. F. (2005). Polícia e sociedade: gestão de segurança pública, violência e controle social. Salvador: EDUFBA.

Deslauriers, J. P., \& Kérisit, M. (2008). O delineamento de pesquisa qualitativa. In: Poupart, J. et al. A pesquisa qualitativa: enfoques epistemológicos e metodológicos. Petrópolis: Ed. Vozes, p.127-153.

Ferreira, P. S. (2017). Uma leitura da produção de estatísticas de homicídios em Salvador. Revista de Estudos Empíricos em Direito, vol. 4, n. 1, fev 2017, p. 94-113

Flauzina, A. L. (2006). Corpo negro caído no chão: sistema penal e o projeto genocida do estado brasileiro. dissertação (mestrado) - pós-graduação em direito, Universidade de Brasília, Brasília.

Fórum Brasileiro de Segurança Pública. (2016). Anuário Brasileiro de Segurança Pública 2016, Ano 10, Edição 2016.

Gloeckner, R. J., \& Gonçalves, P. G. (2017). Letalidade policial e ministério público: das práticas de extermínio ao discurso legitimador. in. Vilares, F. (Org.). Revista brasileira de ciências criminais: dossiê especial letalidade policial, v. 25, n. 130, abr., p. 177-202.

Lima, R. S.; Nunes, S. B. (2012). A opaca estética da indiferença: letalidade policial e políticas públicas de segurança. In. Núcleo De Estudos Da Violência Da Universidade De São Paulo. $5^{\circ}$ Relatório Nacional sobre os Direitos Humanos no Brasil 2001-2010. São Paulo: Centro de Pesquisa, Inovação e Difusão Fundação de Amparo à Pesquisa do Estado de São Paulo.

Macedo, H. L. S. (2015). "Confrontos" de ROTA: a intervenção policial com "resultado morte" no estado de São Paulo. Dissertação de mestrado. Universidade Federal de São Carlos. Programa de Pós-Graduação em Sociologia. São Carlos, 2015.

Machado, I. S.; Ribeiro, L. M. L. (2016). A resposta judicial para homicídios envolvendo policiais no Brasil: uma análise quantitativa. Canadian Journal of Latin American and Caribbean Studies, vol. 41, n. 3, p. 366388.

Machado, M. R.; Machado, M. R. A. (org.). (2015) Carandiru não é coisa do passado [recurso eletrônico]: um 
balanço sobre os processos, as instituições e as narrativas 23 anos após o massacre. São Paulo: FGV Direito SP.

Machado, M. R.; Machado, M. R. A.; Ferreira, L. M. A.; (2012) Massacre do Carandiru: vinte anos sem responsabilização. Novos estudos - CEBRAP, n.94, São Paulo Nov. p. 05-29.

Miranda, A. P. M.; Dirk, R.; Pita, M. V. Análise comparada (Rio de Janeiro e Buenos Aires) das políticas de produção de registros estatísticos criminais. Anais do $37^{\circ}$ Encontro Anual da ANPOCS de 22 a 26 de outubro de 2007, Caxambu, Minas Gerais.

Misse, M.; Grilo, C. C.; Teixeira, C.r P.; Neri, N. E. (2013) Quando a polícia mata: homicídios por "autos de resistência" no Rio de Janeiro (2001-2011). Rio de Janeiro: CNPQ/NECVU/Booklink.

et. al. (2013). Quando a polícia mata: homicídios por "autos de resistência" no Rio de Janeiro (20012011). Rio de Janeiro: Booklink/NECVU.

Nunes, S. B. (2014). Bandido bom é bandido morto: A opção ideológico-institucional da política de segurança pública na manutenção de padrões de atuação violentos da polícia militar paulista. Dissertação de Mestrado. Fundação Getúlio Vargas, Escola de Administração de Empresas de São Paulo. São Paulo, 146 p. O'Donnell, G. (1998). "Polyarchies and the (Un)Rule of Law in Latin America", Paper presented at the Meeting of the Latin American Studies Association, Chicago, September.

Pinheiro, P. S. (1997). Violência, crime e sistemas policiais em países de novas democracias. Tempo Social: Revista de Sociologia da USP, São Paulo, maio, vol. 9, n. 1, p. 43-52.

Pires, A. Amostragem e pesquisa qualitativa: ensaio teórico e metodológico. In: POUPART, Jean. et al. (Org.) A pesquisa qualitativa: enfoques epistemológicos e metodológicos. Petrópolis: Vozes, 2008. p. 154-211.

Reis, V. (2005). Atucaiados pelo Estado: as políticas de segurança pública implementadas nos bairros populares de salvador e suas representações, 1991- 2001. 247f. Dissertação (Mestrado em Ciências Sociais), Universidade Federal da Bahia, Faculdade de Filosofia e Ciências Humanas.

Sen, Amartya. (2000). Desenvolvimento como liberdade. São Paulo: Companhia das Letras.

Sinhoretto, J.; Silvestre, G.; Schlittler, M. C. (2014). Desigualdade racial e segurança pública em São Paulo: letalidade policial e prisões em flagrante. São Carlos: Universidade Federal de São Carlos.
Souza, T. L. S. (2010). Constituição, segurança pública e estado de exceção permanente: a biopolítica dos autos de resistência. 2010. 222f. Dissertação (Mestrado em Direito), Pontifícia Universidade Católica do Rio de Janeiro, Departamento de Direito, 2010.

Vieira, O. V. (2015). Inequality and the subversion of the rule of law. In: RODRÍGUEZ-GARAVITO, César. (Org.). Law and Society in Latin America: A New Map (Law, Development and Globalization). 1ed. New York: Routledge Taylor \& Francis Group a Glass House Book, V., p. 23-42.

Vieira, O. V. (2007). A desigualdade e a subversão do Estado de Direito. Sur, Rev. int. direitos humanos, vol.4, n.6, p.28-51.

Webley, L. (2010). "Qualitative approaches to empirical legal research". In__. The Oxford Handbook to empirical legal research. Oxford: Cane and Kritzer (eds.). Zaccone D'elia Filho, O. (2015). Indignos de vida: a forma jurídica da política de extermínio de inimigos na cidade do Rio de Janeiro. Rio de Janeiro: Revan.

Data de submissão: 30/10/2017

Data de aceite: 13/07/2018 